\title{
Use of Berlin questionnaire in comparison to polysomnography and home sleep study in patients with obstructive sleep apnea
}

\author{
Susanna S. Ng ${ }^{1,2}$, Wilson Tam³ ${ }^{3}$ Tat-On Chan ${ }^{1,2}$, Kin-Wang To ${ }^{1,2}$, Jenny Ngai ${ }^{1,2}$, Ken K. P. Chan ${ }^{1,2}$, Wing-Ho Yip ${ }^{1,2}$,
} Rachel L. Lo ${ }^{1,2}$, Karen Yiü ${ }^{1,2}$, Fanny W. Ko ${ }^{1,2}$ and David S. Hui ${ }^{1,2,3,4^{*}}$

\begin{abstract}
Background: Obstructive sleep apnea syndrome (OSAS) is a common disorder with significant morbidity and mortality. We aimed to evaluate the predictive accuracy of the Berlin questionnaire in patients with suspected OSAS undergoing PSG in the sleep laboratory setting against those going through the Embletta ${ }^{\text {TM }}$ portable diagnostic system (Embletta PDS) at home.

Methods: Patients with suspected OSAS were recruited from respiratory clinics to complete Berlin questionnaire and Epworth Sleepiness Score (ESS). Patients were randomized to undergo either home-based sleep test (group A) or hospital-based polysomnography (PSG) (group B).

Results: Three hundreds and sixteen subjects with newly referred suspected OSAS were recruited and randomized into group A $(n=157)$ and group B $(n=159)$. The prevalence of moderate to severe OSAS defined as apneahypopnea index $(\mathrm{AHI}) \geq 15 / \mathrm{h}$ was $54 \%$. The Berlin questionnaire identified $69.7 \%(n=99)$ of subjects as high risk in group A and $77.5 \%(n=100)$ in group B. The sensitivity, specificity, negative predictive value (NPV), and positive predictive value (PPV) of the questionnaire to predict an AHI $\geq 15 / \mathrm{h}$ as diagnosed by PSG was 78, 23, 67 and 35\%. When compared with Embletta PDS, the specificity and NPV increased to 48 and 63\%. The area under the Receiver Operator Curve (ROC) based on PSG (AUC $=0.539,95 \% \mathrm{Cl} 0.417,0.661)$ and based on home Embletta (AUC $=0.712$, $95 \% \mathrm{Cl} 0.617,0.907)$.
\end{abstract}

Conclusions: The questionnaire was not reliable in predicting OSAS through PSG AHI whereas there was some predictive ability in discriminating patients with OSAS from normal subjects based on home Embletta sleep test.

Trial registration: The study was registered at ClinicalTrials.gov (Identifier: NCT01828216) on 10 April 2013.

Keywords: Obstructive sleep apnea, Questionnaire, Polysomnography, Risk, Sensitivity and specificity

\section{Background}

Obstructive sleep apnea syndrome (OSAS) is a common disorder with prevalence rates of at least $4 \%$ among the middle-aged male Caucasians and Hong Kong (HK) Chinese populations [1-3]. It is characterized by repetitive episodes of upper airway obstruction, causing intermittent hypoxia, sleep fragmentation, disabling daytime sleepiness,

\footnotetext{
* Correspondence: dschui@cuhk.edu.hk

'Division of Respiratory Medicine, The Chinese University of Hong Kong, Sha Tin, Hong Kong

${ }^{2} \mathrm{SH}$ Ho Sleep Apnoea Management Center, The Chinese University of Hong Kong, Sha Tin, Hong Kong

Full list of author information is available at the end of the article
}

impaired cognitive function and poor health status [4]. OSAS patients are at increased risks of cardiovascular morbidity and mortality including sudden death, $[5,6]$ in addition to being more prone to road traffic accidents [7]. Despite the availability of effective therapy such as continuous positive airway pressure (CPAP), OSAS is under-diagnosed in the general population because of limited access to sleep laboratories for nocturnal polysomnography (PSG), which is labor-intensive and currently regarded as the gold standard for confirmation of sleep apnea $[8,9]$. Although the use of validated portable monitoring devices is proven to shorten waiting time and save cost, [10] the next impediment to the diagnosis is the 
relative lack of qualified sleep physicians. Simplified strategies with the use of questionnaires have been proposed to help predicting OSAS in the primary care setting [11, 12]. Berlin questionnaire has been developed as a tool in screening OSAS and validated in primary care [13]. It categorizes patients as either high or low risk for OSAS based on self-reports of snoring, daytime sleepiness, hypertension and obesity. However, most published studies validating its use in predicting OSAS were compared against PSG [13-15] with variable results in sensitivity and specificity. While there is a growing use of portable home monitoring in diagnosing OSAS, the performance of this questionnaire against the portable monitoring devices and PSG is needed.

\section{Methods}

This study aimed to evaluate the accuracy of the Berlin questionnaire in patients with suspected OSAS in comparisons against PSG in the sleep laboratory setting and the Embletta ${ }^{\mathrm{Tm}}$ portable diagnostic system (Embletta PDS) at home.

This study is an ancillary study of a randomized controlled trial (RCT) regarding the use of ambulatory approach versus the hospital-based approach in managing 316 clinic patients with suspected OSAS [10]. Patients with new referrals to the Respiratory Clinic, Prince of Wales Hospital, Shatin, were recruited from 25 September 2013 to 31 August 2014. OSAS was defined by apnea-hypopnea index $(\mathrm{AHI}) \geq 5 / \mathrm{h}$ of sleep plus excessive daytime sleepiness or two of the following symptoms: choking or gasping during sleep, recurrent awakenings from sleep, unrefreshed sleep, daytime fatigue, and impaired concentration [16].

Patients aged 18-80 years with suspected OSAS underwent assessment at the clinic with the Epworth sleepiness score (ESS) [17] and symptoms evaluation. Patients who had ESS score $>9$ or at least two OSAS symptoms as described above were invited to join the study. Exclusion criteria included patients with (a) unstable cardiovascular diseases (e.g. recent unstable angina, myocardial infarction, stroke within the previous 6 months or severe left ventricular failure), (b) neuromuscular disease affecting respiratory muscles, (c) moderate to severe respiratory disease or documented hypoxemia or awake $\mathrm{SaO} 2<92 \%$ or (d) psychiatric disease that limited the ability to give informed consent. Full informed consent and baseline demographic data were obtained. Patients completed the Berlin questionnaire before randomization into either home-based management approach (Group A) or hospital-based management approach (Group B). Randomization was performed by a computerized random table into either group
A) home-based management approach or group B) hospital-based management approach by a third party not involved in the trial [10].

Patients in group A underwent a level 3 validated home sleep study with the Embletta device (Embletta ${ }^{\text {mi }}$ PDS) (Medcare, Iceland) [18] which is a pocket-sized, digital, multi-channel recording device that measures airflow through a nasal cannula connected to a pressure transducer, providing an AHI based on recording time. It also detects both respiratory and abdominal efforts through the effort sensor and can differentiate between obstructive and central events. Built-in position sensors are also available to differentiate supine and non supine events. Patients were instructed by nurses how to operate the device for the sleep recording and estimate their time of sleep. Respiratory events were scored when desaturations of at least $4 \%$ occurred in the absence of moving artifacts and irrespective of co-existing changes in snoring or heart rate. The Embletta ${ }^{\mathrm{Tm}}$ PDS default settings for apneas and hypopneas were used in this study. An apnea was defined as a decrease in airflow by $80 \%$ of baseline for at least $10 \mathrm{~s}$. A hypopnea was defined as a decrease in airflow by $50 \%$ of baseline for at least $10 \mathrm{~s}$. The Embletta $^{\text {Tw }}$ PDS AHI used for analysis was automatically analyzed by the Embletta ${ }^{\mathrm{m}}$ PDS software which was available for reviewing and rescoring by the clinician [18].

Patients in group B underwent overnight PSG (Alice LE, Respironics, USA) at the hospital recording electroencephalogram (EEG), electro-oculogram, submental electromyogram (EMG), bilateral anterior tibial EMG, electrocardiogram, chest and abdominal wall movement by inductance plethysmography, airflow measured by a nasal pressure transducer [PTAF2, Pro-Tech, Woodinville, WA, USA] and supplemented by an oral thermister, and finger pulse oximetry as described in our previous studies $[19,20]$. Apnea was defined as cessation of airflow for $>10 \mathrm{~s}$ with drop in the peak thermal sensor excursion by $\geq 90 \%$ of baseline whereas hypopnea as a reduction of nasal pressure airflow of $\geq 30 \%$ of baseline for $>10$ s plus an oxygen desaturation of $\geq 4 \%$ [21]. This study was approved by the Ethics Committees of the Chinese University of Hong Kong (CREC-2011.215-T) and registered at ClinicalTrials.gov (Identifier: NCT01828216). Written informed consent was obtained from all subjects enrolled in this study.

\section{Statistical analysis}

The results of the Berlin questionnaire were compared with the AHI obtained by PSG and the portable home monitoring by the Embletta ${ }^{\mathrm{ma}}$ PDS using sensitivity, specificity, positive predictive value (PPV) and negative predictive value (NPV) to evaluate the efficacy of the 
questionnaire to screen and assess severity of OSAS with different AHI cut-off at AHI $>5 \mathrm{~h},>15 / \mathrm{h}$ and $>30 \mathrm{~h}$, which corresponded to mild, moderate and severe disease respectively. The comparisons were plotted graphically using receiver operating characteristic (ROC) curve analysis. The greater the area under the curve, the better the instrument would be. Data were analyzed by the Statistical Package of the Social Science (SPSS) for Windows, Version 22.0 (SPSS Inc., Chicago, IL, USA).

\section{Results}

Altogether 316 subjects newly referred with OSAS symptoms were recruited and randomized into group A $(n=157)$ and group B $(n=159)$ as shown in Fig. 1. All of them had completed the Berlin questionnaire before sleep studies. The prevalence of moderate to severe OSAS defined as apnea-hypopnea index (AHI) $\geq 15 / \mathrm{h}$ was $54 \%$ (86 subjects in both group A and B). In group A, eight subjects defaulted and 7 failed the sleep tests, while 5 failed PSG and 25 refused to continue the study in group B. After exclusion of those who did not complete the sleep studies, the Berlin questionnaire identified $69.7 \%(n=99)$ of subjects as high risk in group A and $77.5 \%(n=100)$ in group B.. Table 1 shows the baseline characteristics between the two groups which were similar for most of the variables except for lower $\mathrm{AHI}$ and higher ESS in group A.

Figure 2 shows the sensitivity, specificity, positive (PPV) and negative predictive value (NPV) of the result from Berlin questionnaire when compared against PSG and home sleep monitroing Embletta ${ }^{\mathrm{Tm}}$ PDS. The sensitivity of the questionnaire was $>75 \%$ at all AHI levels among two groups, with the highest results at $\mathrm{AHI} \geq 5 / \mathrm{h}$ in PSG (sensitivity 0.802 ) and AHI $\geq 30 / h$ in home study group (sensitivity 0.884 ). The questionnaire was shown to have excellent PPV at low AHI level (0.890 in PSG and 0.939 in home study group at $\mathrm{AHI} \geq 5 / \mathrm{h}$ ) and NPV at high AHI level (0.655 in PSG and 0.884 in home study group at $\mathrm{AHI} \geq 30 / \mathrm{h}$ ). There are significant differences in the specificity of the questionnaire in comparisons to PSG and home sleep study at the AHI level of $\geq 15$ and $\geq$ $30 / \mathrm{h}$ with higher correlation of the questionnaire with the home sleep study. The questionnaire also showed higher NPV when compared with home sleep study than with PSG at the AHI level of $\geq 15$ and $\geq 30 / h$. The results of individual items including the likelihood ratios of the questionnaire when compared against PSG and AHI are shown in Table 2.

Further analysis of the diagnostic accuracy of the Berlin questionnaire in assessing AHI was performed with the ROC based on PSG (area under curve $(A U C)=$ 0.539. 95\%CI 0.417, 0.661) and based on home Embletta

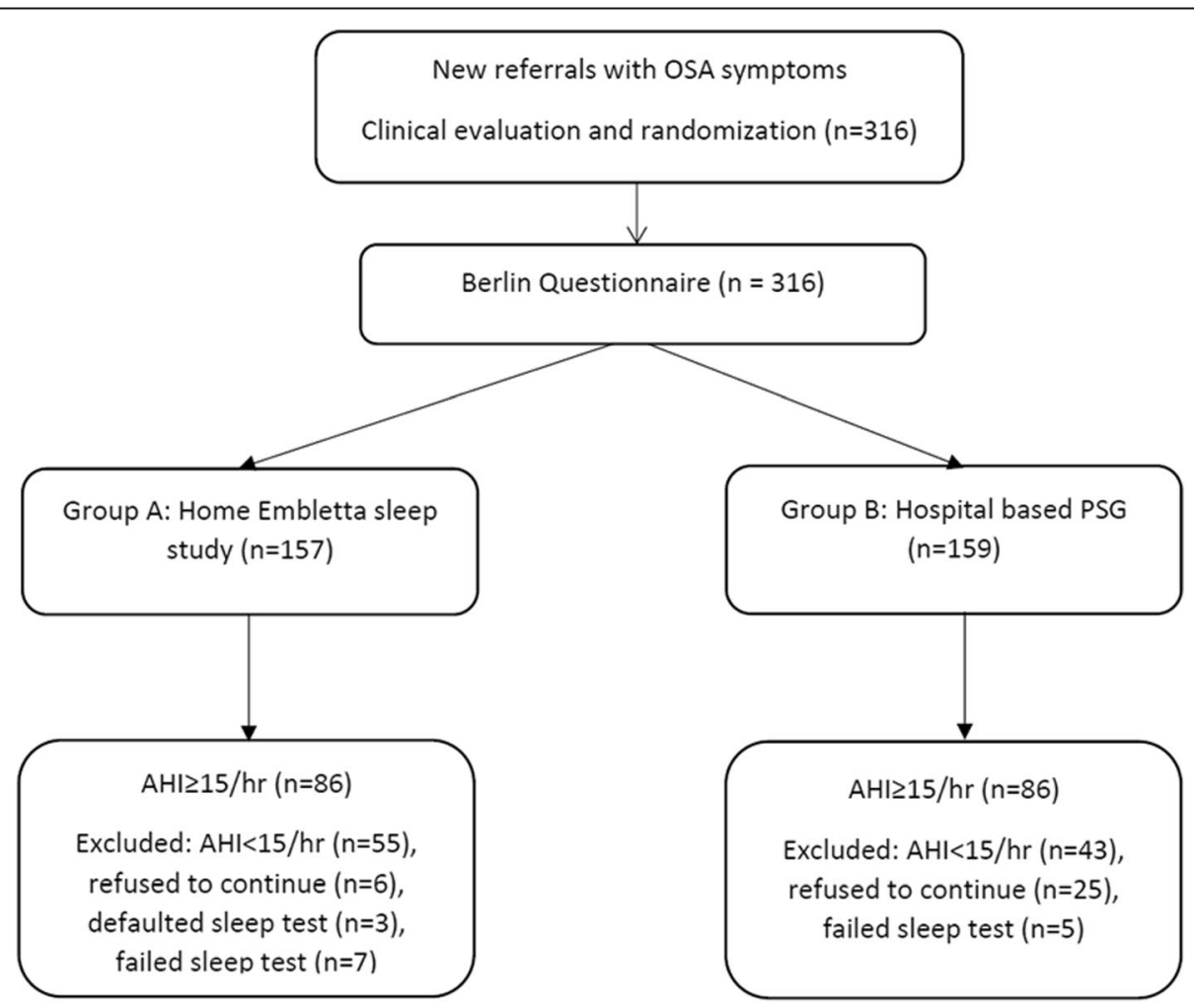

Fig. 1 Flow chart of the study. Consort diagram of participants randomized to the home-based versus hospital-based management pathways 
Table 1 Baseline characteristics between home-based (Group A) vs hospital-based approach (Group B) for diagnosis of OSAS

\begin{tabular}{llll}
\hline & Home $(n=157)$ & Hospital $(n=159)$ & $P$-value \\
\hline Age & $51.0(12.9)$ & $52.1(11.3)$ & 0.403 \\
Male sex [n(\%)] & $107(68.2 \%)$ & $118(74.2 \%)$ & 0.264 \\
Current smoker [n(\%)] & $20(12.8 \%)$ & $24(15.1 \%)$ & $31(26.3 \%)$ \\
Current drinker [n(\%)] & $26(23.0 \%)$ & $5(3.1 \%)$ & 0.691 \\
Congestive Heart Failure [n(\%)] & $6(3.8 \%)$ & $30(18.9 \%)$ & 0.765 \\
Diabetes Mellitus [n(\%)] & $25(15.9 \%)$ & $86(54.1 \%)$ & 0.769 \\
Hypertension [n(\%)] & $72(45.9 \%)$ & $2(1.3 \%)$ & 0.554 \\
Stroke [n(\%)] & $5(3.2 \%)$ & $11(6.9 \%)$ & 0.177 \\
Ischemic Heart Disease [n(\%)] & $9(5.7 \%)$ & $32(20.1 \%)$ & 0.281 \\
Hyperlipidemia [n(\%)] & $32(20.4 \%)$ & $28.3(4.6)$ & 0.818 \\
BMI (kg/m²) & $27.4(5.3)$ & $39.6(3.8)$ & 1.000 \\
Neck circumference (cm) & $38.6(3.6)$ & $97.3(11.2)$ & 0.115 \\
Waist circumference (cm) & $95.4(12.1)$ & $101.6(8.1)$ & 0.013 \\
Hip circumference (cm) & $102.2(9.5)$ & $9.6(5.4)$ & 0.171 \\
ESS (0-24) & $11.0(5.6)$ & $30.8(27.5)$ & 0.527 \\
AHI (events/hr) & $24.1(20.7)$ & $22.6(23.4)$ & 0.025 \\
ODI (events/hr)* & $21.7(19.8)$ & $102(77.3 \%)$ & $30(22.7 \%)$ \\
Berlin questionnaire (high risk) [n(\%)] & $102(65.5 \%)$ & $47(31.5 \%)$ & 0.023 \\
Berlin questionnaire (low risk) [n(\%)] & & 0.724 \\
\hline
\end{tabular}

study $(\mathrm{AUC}=0.712,95 \% \mathrm{CI} 0.617,0.907)$ (Fig. 3). The questionnaire was not reliable in predicting OSAS through PSG AHI whereas there was some predictive ability in discriminating patients with OSAS from normal subjects based on home Embletta sleep test.

\section{Discussion}

This study is the first study comparing the diagnostic accuracy of the Berlin qeuestionnaire in predicting the diagnosis of OSAS determined by PSG and home sleep test. Though the questionnaire has shown a high sensitivity in screening for the disease, it has poor specificity in the diagnosis. The Berlin questionnaire is a commonly used questionnaire in epidemiological and clinical research with variable sensitivity and specificity in different studies [22-26]. One of the reasons for the variability is related to the method in the validation. With the growing literature in support of the ambulatory approach as an alternative strategy in managing patients with a high clinical probability of OSAS, home-based management approach is shown to be more cost effective with shorter waiting time and substantial cost savings in the diagnosis of OSAS when compared with inhospital PSG [10]. This Embletta $^{\text {TM }}$ PDS has been validated in various studies $[18$, 27] against simultaneous PSG with high sensitivity and specificity. As the device is a type III monitor without measurement of EEG, total recording time was used as the denominator in calcuating the AHI, which could be underestimated if the sleep quality was not good. This is in concordance with the higher specificity and NPV of the questionnaire against Embletta ${ }^{\mathrm{im}}$ PDS when compared with that against PSG. Recently, Tan et al validated the use of the Berlin qestionnaire in predicting OSAS as diagnosed by the Embletta device with high specificity throughout different AHI [26]. In contrast to our findings, the sensitivity of the questionnaire was $58.8 \%$ in predicting an $\mathrm{AHI} \geq 15 / \mathrm{h}$ while it rose to $76.9 \%$ in predicting severe OSAS. Thus the use of questionnaire is useful only in predicting patients with severe OSAS. The latest meta-analysis with review on the questionnaire's diagnostic utility against PSG showed similarly good sensitivity for detecting clinically relevant OSAS in the sleep clinic population, but low specificity in screening the general populations [28]. Nevertheless, the high PPV of the questionnaire in those patients having $\mathrm{AHI}>5 / \mathrm{h}$ in may help selecting patients with suspected disease to have fast track investigation, especially among those with cardiovascular comorbidites.

While the Berlin Quesionnaire categorizes patients into high or low risk for OSAS according to symptoms and body mass index (BMI), STOP-Bang questionnaire is another validated screening tool with four subjective (STOP: Snoring, Tiredness, Observed apnea and high blood Pressure) and four demographic items (Bang: BMI, Age, Neck circumference, Gender) [15]. This questionnaire has been widely used in preoperative clinics 


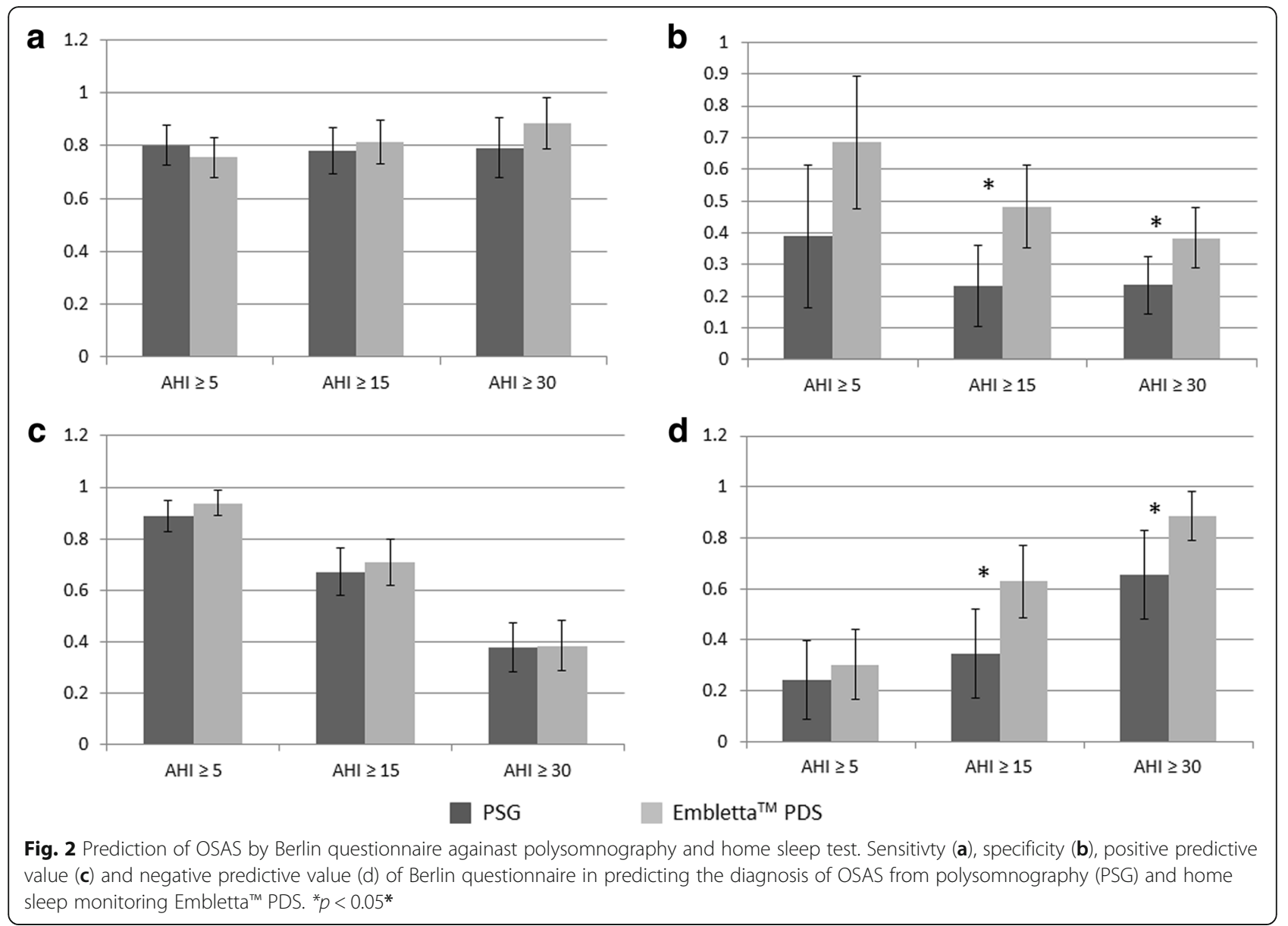

$[15,29]$, sleep clinics $[30,31]$ and the general populations [32] for predicting patients at high risk of OSAS. A meta-analysis showed that the probability of moderate and severe OSAS steadily increased with a higher STOP-Bang score in patients at high risk of OSAS [33]. However, the evidence of its use in general population is not known. The US Preventive Services Task Force (USPSTF) has commented that none of the potential screening questionnaires and clinical prediction tools including ESS, STOP questionnaire, STOP-Bang questionnaires, the Berlin Questionnaire, Wisconsin Sleep Questionnaire, and the Multivariable Apnea Prediction

Table 2 Comparison of the performance of the individual items with confidence intervals in the Berlin questionnaire for prediction of OSA against polysomnography and home sleep study

\begin{tabular}{|c|c|c|c|c|c|c|}
\hline & \multicolumn{2}{|l|}{$\mathrm{AHI} \geq 5 / \mathrm{h}$} & \multicolumn{2}{|l|}{$\mathrm{AHI} \geq 15 / \mathrm{h}$} & \multicolumn{2}{|l|}{$\mathrm{AHI} \geq 30 / \mathrm{h}$} \\
\hline & $\overline{P S G}$ & Embletta & PSG & Embletta & PSG & Embletta \\
\hline Sensitivity & $\begin{array}{l}0.80 \\
(0.73,0.88)\end{array}$ & $\begin{array}{l}0.76 \\
(0.68,0.83)\end{array}$ & $\begin{array}{l}0.78 \\
(0.69,0.87)\end{array}$ & $\begin{array}{l}0.81 \\
(0.73,0.90)\end{array}$ & $\begin{array}{l}0.79 \\
(0.68,0.91)\end{array}$ & $\begin{array}{l}0.88 \\
(0.79,0.98)\end{array}$ \\
\hline Specificity & $\begin{array}{l}0.39 \\
(0.16,0.61)\end{array}$ & $\begin{array}{l}0.68 \\
(0.48,0.89)\end{array}$ & $\begin{array}{l}0.23 \\
(0.11,0.36)\end{array}$ & $\begin{array}{l}0.48 \\
(0.35,0.61)\end{array}$ & $\begin{array}{l}0.24 \\
(0.14,0.33)\end{array}$ & $\begin{array}{l}0.38 \\
(0.29,0.48)\end{array}$ \\
\hline PPV & $\begin{array}{l}0.89 \\
(0.83,0.95)\end{array}$ & $\begin{array}{l}0.94 \\
(0.89,0.99)\end{array}$ & $\begin{array}{l}0.67 \\
(0.58,0.76)\end{array}$ & $\begin{array}{l}0.71 \\
(0.62,0.80)\end{array}$ & $\begin{array}{l}0.38 \\
(0.29,0.48)\end{array}$ & $\begin{array}{l}0.38 \\
(0.29,0.48)\end{array}$ \\
\hline NPV & $\begin{array}{l}0.24 \\
(0.09,0.40)\end{array}$ & $\begin{array}{l}0.30 \\
(0.17,0.44)\end{array}$ & $\begin{array}{l}0.35 \\
(0.17,0.52)\end{array}$ & $\begin{array}{l}0.63 \\
(0.48,0.77)\end{array}$ & $\begin{array}{l}0.66 \\
(0.48,0.83)\end{array}$ & $\begin{array}{l}0.88 \\
(0.79,0.98)\end{array}$ \\
\hline LR+ & $\begin{array}{l}1.31 \\
(0.90,1.91)\end{array}$ & $\begin{array}{l}2.39 \\
(1.23,4.68)\end{array}$ & $\begin{array}{l}1.02 \\
(0.83,1.24)\end{array}$ & $\begin{array}{l}1.57 \\
(1.20,2.06)\end{array}$ & $\begin{array}{l}1.03 \\
(0.86,1.25)\end{array}$ & $\begin{array}{l}1.43 \\
(1.19,1.73)\end{array}$ \\
\hline LR- & $\begin{array}{l}0.51 \\
(0.26,1.02)\end{array}$ & $\begin{array}{l}0.36 \\
(0.23,0.55)\end{array}$ & $\begin{array}{l}0.95 \\
(0.49,1.86)\end{array}$ & $\begin{array}{l}0.39 \\
(0.23,0.65)\end{array}$ & $\begin{array}{l}0.89 \\
(0.45,1.75)\end{array}$ & $\begin{array}{l}0.30 \\
(0.12,0.72)\end{array}$ \\
\hline
\end{tabular}



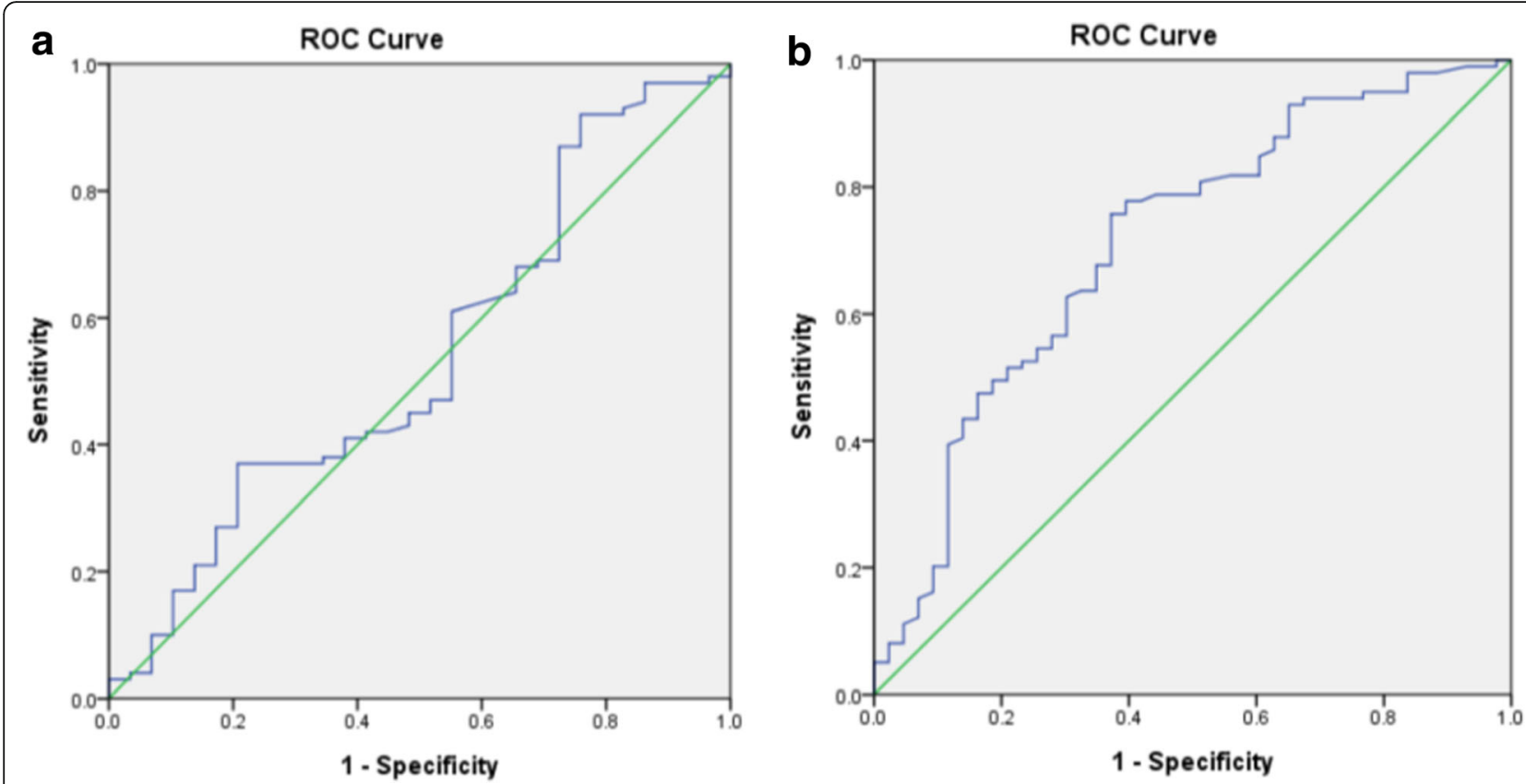

Fig. 3 Diagnostic accuracy of the Berlin questionnaire. Reciever operative curve (ROC) analysis of the diagnostic accuracy of the Berlin questionnaire in assessing AHI based on hospital-based polysomonography (3a) and home Embletta sleep test (3b)

(MVAP) tool have been adequately validated in a primary care setting [34]. The American Academy of Sleep Medicine has also made a strong recommendation that clinical tools, questionnaires and prediction algorithms not be used to diagnose OSA in adults, in the absence of polysomnography or home sleep apnea testing [35].

Our study has several limitations. Firstly, this was an ancillary study from our previous study with sample size originally being powered to demonstrate non-inferiority of the ambulatory approach versus the hospital based approach with respect to change in ESS, the primary outcome measure [10]. Nevertheless, according to the minimum sample size for sensitivity and specificity reported in Bujang and Adnan [36], our current sample size should be enough. Secondly, the baseline characteristic between the two groups were not matched in which increasing the sample size could be helpful to eliminate the difference in the future studies. Thirdly, the Berlin questionnaire was developed as a screening tool for OSAS in unselected, primary care populations while the population we recruited was sleepy and symptomatic patients with ESS $>9$ and at least 2 OSAS related symptoms. The lower diagnostic performance might have been related to exclusion of non-sleepy patients with OSAS. The difference in the studied population may have altered the performance characteristics of the questionnaire. While expecting the Berlin questionnaire to perofrm even better in sleepy patients, our study results might be a conservative estimate of unreliability. Fourthly, different scoring apnea/hypopnea rules for
Embletta PDS and PSG were applied in the study as in prevoius validation study [18], the difference in the scoring rules between the two systems together with the limitation of measuring total recording time instead of actual sleep time could be the potential bias in the difference in AHI.

\section{Conclusion}

The Berlin Questionanire was unreliable in our patient population in predicting OSAS by PSG-AHI whereas the ability to differentiate patients with OSAS from normal was better with home Embletta-AHI.

\section{Abbreviations}

AHI: Apnea-hypopnea index; AUC: Area under curve; BMI: Body mass index; CPAP: Continuous positive airway pressure; EEG: Electroenchelogram; Embletta PDS: Embletta ${ }^{\mathrm{TM}}$ portable diagnostic system; ESS: Epworth Sleepiness Score; HK: Hong Kong; NPV: Negative predictive value; OSAS: Obstructive sleep apnea syndrome; PPV: Positive predictive value; PSG: Polysomnography; RCT: Randomized controlled trial; ROC: Receiver operating characteristic; SPSS: The Statistical Package of the Social Science

\section{Acknowledgements}

Not applicable.

\section{Funding}

This study was funded by the Health \& Medical Research Fund (Ref: 10110811), Food and Health Bureau, Hong Kong, for supporting this study. The study sponsor, Health \& Medical Research Fund, Food \& Health Bureau, Hong Kong, played no role in study design, data collection, analysis, data interpretation in the writing of the report and in the decision to submit the paper for publication. 


\section{Availability of data and materials}

The datasets generated and/or analysed during the current study are not publicly available due to individual privacy but are available from the corresponding author on reasonable request.

\section{Authors' contributions}

SN, WT, DH were responsible for conception and design. TC and KY provided administrative support. KT, JN, KC, WY, RL and FK provided study materials and patients. TC, WT and KY collected and assembled data. SN, DH, WT proceeded data analysis and interpretation. All authors contributed the manuscript writing and approved the final manuscript.

\section{Ethics approval and consent to participate}

All procedures performed in the study involving human participants were in accordance with the ethical standards of the instituional (the Ethics Committees of the Chinese University of Hong Kong (CREC-2011.215-T)) and with the 1964 Helsinki declaration and its later amendments. Informed consent: Informed consent was obtained from all individual participants included in the study.

\section{Consent for publication}

Not applicable.

\section{Competing interests}

The authors declare that they have no competing interests.

\section{Publisher's Note}

Springer Nature remains neutral with regard to jurisdictional claims in published maps and institutional affiliations.

\section{Author details}

${ }^{1}$ Division of Respiratory Medicine, The Chinese University of Hong Kong, Sha Tin, Hong Kong. ${ }^{2} \mathrm{SH}$ Ho Sleep Apnoea Management Center, The Chinese University of Hong Kong, Sha Tin, Hong Kong. ${ }^{3}$ Alice Lee Centre for Nursing Studises, National University of Singapore, Singapore, Singapore.

${ }^{4}$ Department of Medicine and Therapeutics, The Chinese University of Hong Kong, Prince of Wales Hospital, 30-32 Ngan Shing St, Shatin, N.T, Hong Kong.

\section{Received: 26 October 2018 Accepted: 18 February 2019}

\section{Published online: 22 February 2019}

\section{References}

1. Young T, Palta M, Dempsey J, Skatrud J, Weber S, Badr S. The occurrence of sleep-disordered breathing among middle-aged adults. N Engl J Med. 1993; 328(17):1230-5.

2. Bearpark H, Elliott L, Grunstein R, Cullen S, Schneider H, Althaus W, et al. Snoring and sleep apnea. A population study in Australian men. Am J Respir Crit Care Med. 1995:151(5):1459-65.

3. Ip MS, Lam B, Lauder IJ, Tsang KW, Chung KF, Mok YW, et al. A community study of sleep-disordered breathing in middle-aged Chinese men in Hong Kong. Chest. 2001;119(1):62-9.

4. Engleman HM, Douglas NJ. Sleep. 4: sleepiness, cognitive function, and quality of life in obstructive sleep apnoea/hypopnoea syndrome. Thorax 2004;59(7):618-22.

5. Marin JM, Carrizo SJ, Vicente E, Agusti AG. Long-term cardiovascular outcomes in men with obstructive sleep apnoea-hypopnoea with or without treatment with continuous positive airway pressure: an observational study. Lancet. 2005;365(9464):1046-53.

6. Gami AS, Howard DE, Olson EJ, Somers VK. Day-night pattern of sudden death in obstructive sleep apnea. N Engl J Med. 2005;352(12):1206-14.

7. Masa JF, Rubio M, Findley LJ. Habitually sleepy drivers have a high frequency of automobile crashes associated with respiratory disorders during sleep. Am J Respir Crit Care Med. 2000;162(4 Pt 1):1407-12.

8. Collop NA, Anderson WM, Boehlecke B, Claman D, Goldberg R, Gottlieb DJ, et al. Clinical guidelines for the use of unattended portable monitors in the diagnosis of obstructive sleep apnea in adult patients. Portable monitoring task force of the American Academy of sleep medicine. J Clin Sleep Med. 2007:3(7):737-47.

9. Flemons WW, Douglas NJ, Kuna ST, Rodenstein DO, Wheatley J. Access to diagnosis and treatment of patients with suspected sleep apnea. Am J Respir Crit Care Med. 2004;169(6):668-72 Epub 2004/03/09.
10. Hui DS, Ng SS, To KW, Ko FW, Ngai J, Chan KK, et al. A randomized controlled trial of an ambulatory approach versus the hospital-based approach in managing suspected obstructive sleep apnea syndrome. Sci Rep. 2017:8:45901 Epub 2017/04/05.

11. Flemons WW, Whitelaw WA, Brant R, Remmers JE. Likelihood ratios for a sleep apnea clinical prediction rule. Am J Respir Crit Care Med. 1994;150(5 Pt 1):1279-85 Epub 1994/11/01.

12. Tsai WH, Remmers JE, Brant R, Flemons WW, Davies J, Macarthur C. A decision rule for diagnostic testing in obstructive sleep apnea. Am J Respir Crit Care Med. 2003;167(10):1427-32 Epub 2003/05/10.

13. Netzer NC, Stoohs RA, Netzer CM, Clark K, Strohl KP. Using the Berlin questionnaire to identify patients at risk for the sleep apnea syndrome. Ann Intern Med. 1999:131(7):485-91 Epub 1999/10/03.

14. Sharma SK, Vasudev C, Sinha S, Banga A, Pandey RM, Handa KK. Validation of the modified Berlin questionnaire to identify patients at risk for the obstructive sleep apnoea syndrome. Indian J Med Res. 2006;124(3):281-90 Epub 2006/11/07.

15. Chung F, Yegneswaran B, Liao P, Chung SA, Vairavanathan S, Islam S, et al. STOP questionnaire: a tool to screen patients for obstructive sleep apnea. Anesthesiology. 2008;108(5):812-21 Epub 2008/04/24.

16. Sleep-related breathing disorders in adults: recommendations for syndrome definition and measurement techniques in clinical research. The Report of an American Academy of Sleep Medicine Task Force. Sleep. 1999;22(5):66789. Epub 1999/08/18.

17. Johns MW. A new method for measuring daytime sleepiness: the Epworth sleepiness scale. Sleep. 1991;14(6):540-5 Epub 1991/12/01.

18. Ng SS, Chan TO, To KW, Ngai J, Tung A, Ko FW, et al. Validation of Embletta portable diagnostic system for identifying patients with suspected obstructive sleep apnoea syndrome (OSAS). Respirology. 2010;15(2):336-42 Epub 2010/03/05

19. Hui DS, To KW, Ko FW, Fok JP, Chan MC, Ngai JC, et al. Nasal CPAP reduces systemic blood pressure in patients with obstructive sleep apnoea and mild sleepiness. Thorax. 2006;61(12):1083-90 Epub 2006/08/25

20. Hui DS, Ko FW, Fok JP, Chan MC, Li TS, Tomlinson B, et al. The effects of nasal continuous positive airway pressure on platelet activation in obstructive sleep apnea syndrome. Chest. 2004;125(5):1768-75 Epub 2004/ 05/12.

21. Flemons WW, Reimer MA. Development of a disease-specific health-related quality of life questionnaire for sleep apnea. Am J Respir Crit Care Med. 1998;158(2):494-503 Epub 1998/08/12.

22. Danzi-Soares NJ, Genta PR, Nerbass FB, Pedrosa RP, Soares FS, Cesar LA, et al. Obstructive sleep apnea is common among patients referred for coronary artery bypass grafting and can be diagnosed by portable monitoring. Coron Artery Dis. 2012;23(1):31-8 Epub 2011/11/24.

23. Drager LF, Genta PR, Pedrosa RP, Nerbass FB, Gonzaga CC, Krieger EM, et al. Characteristics and predictors of obstructive sleep apnea in patients with systemic hypertension. Am J Cardiol. 2010;105(8):1135-9 Epub 2010/04/13.

24. Laporta R, Anandam A, El-Solh AA. Screening for obstructive sleep apnea in veterans with ischemic heart disease using a computer-based clinical decision-support system. Clin Res Cardiol. 2012;101(9):737-44 Epub 2012/ 04/06.

25. Nunes FS, Danzi-Soares NJ, Genta PR, Drager LF, Cesar LA, Lorenzi-Filho G. Critical evaluation of screening questionnaires for obstructive sleep apnea in patients undergoing coronary artery bypass grafting and abdominal surgery. Sleep Breath. 2015:19(1):115-22 Epub 2014/03/29.

26. Tan A, Yin JD, Tan LW, van Dam RM, Cheung YY, Lee CH. Using the Berlin questionnaire to predict obstructive sleep apnea in the general population. J Clin Sleep Med. 2017;13(3):427-32 Epub 2016/11/20.

27. Dingli K, Coleman EL, Vennelle M, Finch SP, Wraith PK, Mackay TW, et al. Evaluation of a portable device for diagnosing the sleep apnoea/ hypopnoea syndrome. Eur Respir J. 2003;21(2):253-9 Epub 2003/03/01.

28. Senaratna CV, Perret JL, Matheson MC, Lodge CJ, Lowe AJ, Cassim R, et al. Validity of the Berlin questionnaire in detecting obstructive sleep apnea: a systematic review and meta-analysis. Sleep Med Rev. 2017; Epub 2017/06/ 11.

29. Chung F, Subramanyam R, Liao P, Sasaki E, Shapiro C, Sun Y. High STOPBang score indicates a high probability of obstructive sleep apnoea. $\mathrm{Br}$ J Anaesth. 2012;108(5):768-75 Epub 2012/03/10.

30. Ong TH, Raudha S, Fook-Chong S, Lew N, Hsu AA. Simplifying STOP-BANG use of a simple questionnaire to screen for OSA in an Asian population. Sleep Breath. 2010;14(4):371-6 Epub 2010/04/27. 
31. Farney RJ, Walker BS, Farney RM, Snow GL, Walker JM. The STOP-Bang equivalent model and prediction of severity of obstructive sleep apnea: relation to polysomnographic measurements of the apnea/hypopnea index. J Clin Sleep Med. 2011;7(5):459-65B Epub 2011/10/18.

32. Silva GE, Vana KD, Goodwin JL, Sherrill DL, Quan SF. Identification of patients with sleep disordered breathing: comparing the four-variable screening tool, STOP, STOP-Bang, and Epworth sleepiness scales. J Clin Sleep Med. 2011;7(5):467-72 Epub 2011/10/18.

33. Nagappa M, Liao P, Wong J, Auckley D, Ramachandran SK, Memtsoudis S, et al. Validation of the STOP-Bang questionnaire as a screening tool for obstructive sleep apnea among different populations: a systematic review and meta-analysis. PLoS One. 2015;10(12):e0143697 Epub 2015/12/15.

34. Bibbins-Domingo K, Grossman DC, Curry SJ, Davidson KW, Epling JW Jr, Garcia FA, et al. Screening for obstructive sleep apnea in adults: US preventive services task force recommendation statement. JAMA. 2017; 317(4):407-14 Epub 2017/01/25.

35. Kapur VK, Auckley DH, Chowdhuri S, Kuhlmann DC, Mehra R, Ramar K, et al. Clinical practice guideline for diagnostic testing for adult obstructive sleep apnea: an American Academy of sleep medicine clinical practice guideline. J Clin Sleep Med. 2017;13(3):479-504 Epub 2017/02/07.

36. Bujang MA, Adnan TH. Requirements for minimum sample size for sensitivity and specificity analysis. J Clin Diagn Res. 2016;10(10):YE01-YE6 Epub 2016/11/29.

Ready to submit your research? Choose BMC and benefit from:

- fast, convenient online submission

- thorough peer review by experienced researchers in your field

- rapid publication on acceptance

- support for research data, including large and complex data types

- gold Open Access which fosters wider collaboration and increased citations

- maximum visibility for your research: over $100 \mathrm{M}$ website views per year

At BMC, research is always in progress.

Learn more biomedcentral.com/submissions 